\title{
IDENTIFIKASI APLIKASI PENGGUNAAN CYBER EXTENSION SEBAGAI SUMBER INFORMASI PENYULUH DALAM ADOPSI TEKNOLOGI PAKAN
}

\author{
(Identification of the Use of Cyber Extension as the Source of Information in \\ Adoption of Feed Technology)
}

\author{
Agustina Abdullah ${ }^{1 *}$, Jamila ${ }^{1}$, Amidah $\mathbf{A}^{\mathbf{1}}$, Amrullah ${ }^{1}$, Syahdar $\mathbf{B}^{1}$ dan Hilda \\ Ibrahim ${ }^{2}$ \\ ${ }^{1}$ Fakultas Peternakan Universitas Hasanuddin, Makassar, Sulawesi Selatan, Kodepos 90245 \\ ${ }^{2}$ Fakultas Pertanian Universitas Islam Makasar, Makassar, Sulawesi Selatan, Kodepos 90245 \\ *Email korespondensi : abdullah_ina@yahoo.com dan agustina.abdullah.@unhas.ac.id \\ Received: 10 October 2018.; Revision: 13 Fabruary 2019; Accepted: 8 March 2019
}

\begin{abstract}
Abstrak
Sektor peternakan memiliki peranan penting dalam mendongkrak perekonomian Indonesia agar bisa tumbuh dengan cepat. Oleh karena itu, proses pembangunan peternakan dalam penggunaan teknologi tidak bisa dikesampingkan, apalagi di era digital saat ini yang hampir semua sektor mengusung revolusi industri 4.0 (industri digital). Penelitian ini bertujuan untuk mengindentifikasi kapasitas penyuluh dalam aplikasi penggunaan cyber extension sebagai sumber informasi penyuluhan untuk adopsi teknologi pakan sapi potong. Penelitian dilaksanakan di Kabupaten Bulukumba Provinsi Sulawesi Selatan. Sumber data penelitian dikumpulkan dengan melakukan survei atau wawancara kepada penyuluh dengan kuesioner, focus group discussion, serta wawancara secara mendalam (indepth study) kepada beberapa informan kunci. Hasil penelitian menunjukkan bahwa aplikasi cyber extension belum tersosialisasi dengan baik ke penyuluh, dan tidak didukung dengan fasilitas laptop. Penyuluh yang tanggap menggunakan fasilitas pribadi seperti laptop (bagi yang memiliki laptop) menggunakan laptop untuk mendapatkan informasi materi penyuluhan tentang teknologi pakan. Peternak akan lebih mudah memahami, menarik, dan mengadopsi jika penyuluhan dilakukan dengan gambaran tentang bahan pakan ternak, bagaimana mengolah pakan yang tersedia di wilayah melalui gambar, dan mau mengikuti anjuran penyuluh karena peternak dapat melihat bukti walaupun hanya melalui tayangan-tayangan yang diperlihatkan penyuluh. Cara lain yang digunakan penyuluh untuk meningkatkan adopsi teknologi pakan dengan fasilitas yang minim yaitu berkolaborasi dengan formulator sales untuk melakukan penyuluhan dengan target penyuluhan yang hendak dicapai adalah peningkatan adopsi teknologi pakan.
\end{abstract}

Kata kunci: cyber extension, kapasitas penyuluh, sapi potong, teknologi pakan

\begin{abstract}
Livestock sector has an essetial role in increasing the Indonesian economic growth. Therefore, the process of developing animal husbandry using technology in the digital era is unavoidable This research is to identify the capacity of extension workers in the use of cyber extension as a source of information on cattle feed technology adoption. The study was conducted in Bulukumba Regency of South Sulawesi Province. Data were collected through interviews using questionnaires, FGD, and indepth interviews to several key informants. The results showed that the use of cyber extension has not been well socialized to extension workers and they are not facilitated with laptop. Those who have laptop are responsive in getting extension material about feed technology. Farmers will more easily understand and adopt by following the advice of and evidence shown by the extension workers. Another method used by the workers to increase adoption of feed technology with minimal facilities is to collaborate with sales formulators. This study concludes that most externsion workers have not used the cyber extension application to obtain extension materials due to the lack of skills in accessing the internet network, inadequate laptop facilities and internet networks. Therefore, government's attention is needed in facilitating the workers to generate participation and welfare of farmers.
\end{abstract}

Keywords: capacity, cyber extension, feed technology, livestock 


\section{PENDAHULUAN}

Sektor peternakan memiliki peranan penting dalam mendongkrak perekonomian Indonesia agar bisa tumbuh dengan cepat. Oleh karena itu, proses pembangunan peternakan penggunaan teknologi tidak bisa dikesampingkan, apalagi di era digital seperti saat ini yang hampir semua sektor mengusung revolusi industri 4.0 (industri digital). Begitupun dengan penyampaian informasi penyuluhan kepada peternak mengalami perkembangan seiring dengan pesatnya perkembangan teknologi informasi dan komunikasi, sehingga menuntut penyuluh untuk meningkatkan kapasitas agar dapat menyesuaikan dengan dinamika perubahan yang terjadi.

Era informasi digital melalui media elektronik dan alur informasi melalui sistem jaringan dunia maya telah merambah ke seluruh pelosok perdesaan dengan adanya jaringan cyber yang semakin meluas (Listiana et al, 2019). Sebagian peternak sudah mengakses informasi peternakan dengan memanfaatkan teknologi informasi seperti telephone seluler. Bahkan sudah ada yang memanfaatkan jaringan internet. Kondisi ini tentunya sangat berpengaruh terhadap penyuluh, yang sebagian besar masih menggunakan cara konvensional dalam melakukan kegiatan penyuluhan di lapangan. Materi penyuluhan yang selama ini didistribusikan secara konvensional baik melalui media cetak (koran, brosur, leaflet, dil), maupun media elektronik (dalam bentuk iklan tayangan, film, saung tani, dll) memerlukan biaya yang relatif besar dan butuh waktu panjang, sementara hasilnya juga belum tentu optimal, (Mulyandari dkk, 2010).

Kementerian Pertanian sudah meluncurkan program penyuluhan berbasis internet. Timbul kesan bahwa dengan metode penyuluhan seperti itu, para penyuluh dianggap stagnant dalam kinerjannya. Secara perlahan metode yang sudah "ketinggalan zaman" itu harus mulai dialihkan dengan metode penyuluhan berbasis internet, karena kalau masih mempertahankan pola konvensional, bukan tidak mungkin para penyuluh justru akan ketinggalan informasi dibanding dengan petani atau peternak yang disuluhnya. Untuk mengantisipasi ketertinggalan tersebut, sejak tahun 2010 diberi nama Cyber Extension.
Melalui aplikasi online ini, para penyuluh dapat dengan mudah mengakses dan menyampaikan materi penyuluhan kepada petani, begitu juga dengan para petani, mereka juga dapat mengakses langsung berbagai informasi pertanian dan materi penyuluhan melalui aplikasi ini. Namun meski sudah diluncurkan selama 6 tahun, belum semua penyuluh pertanian bisa memanfaatkan media penyuluhan online ini sebagai penunjang kinerja mereka. Hal itu disebabkan oleh masih banyaknya penyuluh pertanian yang sampai saat ini masih gagap teknologi. Ini terkait dengan pola penyuluhan konvensional yang mereka anggap sebagai satu-satunya metode penyuluhan, tanpa menyadari bahwa perkembangan teknologi informasi telah melesat begitu jauh kedepan. Selain itu keengganan penyuluh untuk belajar teknologi serta minimnya dukungan kelembagaan penyuluh yang mampu mendorong para penyuluh untuk dapat mengakses teknologi informasi juga ditengarai menjadi penyebab masih lemahnya penguasaan teknologi pertanian oleh para penyuluh pertanian, terutama yang bertugas di daerah.

Harus diakui, di tingkat kelembagaan penyuluh sendiri, khususnya di kabupaten, dukungan pimpinan instansi atau kelembagaan penyuluh terhadap akses informasi berbasis internet juga masih lemah. Banyak pimpinan instansi penyuluhan tingkat kabupaten yang minim kepedulian terhadap pentingnya akses informasi melalui internet, karena yang bersangkutan juga tidak menguasai teknologi tersebut. Kondisi seperti ini tentu saja membuat motivasi penyuluh untuk belajar tentang teknologi informasi menjadi rendah, dan akibatnya masih banyak penyuluh pertanian yang sama sekali tidak mengusai teknologi informasi tersebut. Berdasarkan hal tersebut, tujuan penelitian ini adalah mengidentifikasi aplikasi penggunaan cyber extension sebagai sumber informasi penyuluh dalam adopsi teknologi pakan di Kabupaten Bulukumba Sulawesi Selatan.

\section{METODE PENELITIAN}

Analisis data menggunakan analisis deskriptif. Penelitian dilaksanakan di Kabupaten Bulukumba, Provinsi Sulawesi Selatan. Pengambilan sampel penelitian menggunakan metode sensus yang meliputi keseluruhan jumlah anggota populasi 
(Sugiyono, 2011). Responden pada penelitian ini penyuluh lapangan. Penelitian dirancang dengan mengumpulkan data yang terdiri dari data primer dan data sekunder. Data primer dikumpulkan dengan menggunakan instrumen kuesioner sebagai pedoman dalam melakukan wawancara secara terstruktur, focus group discussion, dan wawancara mendalam (indepth study) kepada beberapa informan kunci.

\section{HASIL DAN PEMBAHASAN}

\section{Identifikasi Pendekatan Penyuluh Dalam Menyampaikan Materi Penyuluhan}

Pendekatan penyuluh dalam memberikan informasi kepada peternak melalui berbagai metode. Metode penyuluhan dapat didasarkan pada media yang digunakan, jumlah sasaran dan, sifat hubungan antara penyuluh dan petani. Penggunaannya berbeda-beda dari satu tempat ke tempat yang lain dan dari satu teknologi ke teknologi yang lain. Berdasarkan hasil survei diidentifikasi bahwa ragam metode yang digunakan dalam setiap pendekatan antara lain :

\section{a. Metode Pendekatan Perseorangan}

Berdasarkan hasil wawancara dengan penyuluh dan peternak di lapangan, salah satu pendekatan penyuluhan yang diterapkan oleh penyuluh pada peternak adalah metode perorangan dengan berkunjung ketempat petani. Metode perseorangan adalah melakukan penyuluhan dengan mendatangi langsung petani di rumah maupun di lahannya. Metode kunjungan yang dilaksanakan oleh penyuluh ke rumah petani tersebut dengan mengidentifikasi permasalahan maupun mencari solusi atas apa yang dihadapi petani.

Pada umumnya di Kabupaten Bulukumba penyuluhan yang dominan diterapkan oleh penyuluh adalah metode perseorangan karena lebih efektif dalam mengidentifikasi kebutuhan dan permasalahan petani. Hal ini sesuai dengan Mardikanto (2008) bahwa jika inovasi tersebut relative sulit disampaikan lewat media massa atau sasaran belum mampu memanfaatkan media massa, inovasi yang disampaikan lewat media antar pribadi akan lebih cepat dapat diadopsi oleh masyarakat sasarannya. Lionberger dan Gwin (1991) menyatakan bahwa seringkali seseorang dari kelompok sasaran yang berskala kecil (pertemuan, demonstrasi atau kunjungan) akan menampilkan fungsi-fungsi komunikasi yang lebih baik karena memungkinkan terjadinya komunikasi antarpribadi didalamnya daripada anggota kelompok sasaran yang berskala besar.

Menurut Rogers (Depari dan MacAndrews, 1985) komunikasi antarpribadi umumnya lebih efektif dalam mengubah sikap. Walaupun demikian, metode ini memiliki kelemahan karena luasnya daerah binaan dan terbatasnya jumlah penyuluh di masing-masing kecamatan serta banyaknya petani dan kelompok tani yang merupakan dampingan penyuluh sehingga pendekatan ini dianggap kurang efesien dari segi waktu. Selain itu terbatasnya fasilitas transportasi (motor) yang dimiliki penyuluh sehingga tidak dapat menjangkau lokasi dan daerah terpencil hal ini menyebabkan penyuluh belum dapat secara optimal dalam mengidentifikasi kebutuhan dan permasalahan petani.

\section{b. Metode Pendekatan Kelompok}

Hasil identifikasi di lapangan dan wawancara dengan penyuluh di Kabupaten Bulukumba pada umumnya metode pendekatan kelompok pada petani ada yang sudah melakukan, namun ada juga masih sangat kurang menerapkannya. Yang masih kurang melakukannya berasumsi bahwa umumnya petani atau peternak tidak dapat hadir pada saat pelaksanaan penyuluhan karena mereka dari pagi hingga sore mengelola lahan pertaniannya. Biasanya metode kelompok diterapkan saat bersamaan dengan kegiatan yang dilaksanakan oleh kantor desa, jadi penyuluh menyampaikan pada acara-acara tersebut.

Selain itu, metode kelompok juga di laksanakan pada saat sosialisasi teknologi yang dilaksanakan oleh distributor/pengusaha sarana produksi pertanian/peternakan. Metode kelompok ini adalah metode yang efisien akan tetapi kurang efektif dalam mengidentifikasi kebutuhan dan permasalahan petani, salah satu faktornya karena petani kurang terbuka menyampaikan permasalahannya di khalayak umum pada saat penyuluhan secara berkelompok. Metode kelompok ini efektif dibandingkan dari metode lainnya karena petani dibimbing dan diarahkan secara berkelompok untuk melakukan sesuatu kegiatan yang lebih produktivitas atas dasar kerjasama. Metode kelompok pada umumnya 
berdaya guna dan berhasil guna tinggi, namun keberadaan kelompok di pedesaan cukup baik dan terorganisir dengan baik dan menjadi kendala bagi penyuluh.

\section{c. Metode Pendekatan Massal}

Berdasarkan hasil identifikasi di beberapa kecamatan di Kabupaten Bulukumba, pada umumnya metode massal digunakan oleh penyuluh pada pengembangan komoditi pada saat musyawarah awal musim, karena pada waktu tersebut dihadirkan para petani, kelompok tani maupun Gapoktan, penyuluh pertanian kabupaten dan kecamatan, stakeholder pertanian lainnya, bahkan juga dihadiri oleh aparat pemerintah daerah baik kabupaten, kecamatan maupun desa serta unsur TNI dan kepolisian (Pujiana et al., 2019). Menurut Shore (Hapsari, 1994; Yanfika et al., 2019) menyatakan bahwa, saluran komunikasi media massa menyajikan berbagai informasi yang berdimensi luas sehingga dapat memperkaya wawasan seseorang dalam beberapa hal. Begitupun dengan (Lionberger dan Gwin,1991) yang menyatakan bahwa meskipun saluran media massa sangat efektif untuk menyalurkan khususnya jenis informasi bersifat umum dan menurut Rogers (Depari dan MacAndrews, 1985) dapat mengubah pendapat (menambah pengetahuan).

Namun demikian menurut Lionberger dan Gwin (1991), kebutuhan komunikasi dinegaranegara berkembang tidak dapat mengandalkan saluran media massa sendiri, akan tetapi kebutuhan saluran media massa dimaksudkan untuk membantu saluran interpersonal bukan menggantikannya. Ditinjau dari efisiensinya penyampaian pesan atau informasi melalui media penyiaran radio ini memang sangat tepat karena dapat menjangkau seluruh wilayah binaan. Akan tetapi cara seperti ini sering kali mengalami distorsi karena informasi yang disampaikan bersifat penerangan dan tidak mengena kepada aspek kognitif dan psikomotorik dari khalayak sasarannya.

\section{Aplikasi Penggunaan Cyber Extension Sebagai Sumber Informasi Penyuluh}

Pemanfaatan teknologi informasi merupakan media baru dalam komunikasi pertanian. Internet merupakan salah satu bentuk revolusi terkait bagaimana kita dapat bekerja untuk mengelola informasi dan berkomunikasi dengan orang lain secara cepat dan tanpa terkendala ruang dan jarak yaitu dengan aplikasi cyber extension yang telah dikembangkan. Namun berdasarkan hasil penelitian di Balai Penyuluhan Pertanian Kabupaten Bulukumba teridentifikasi media yang digunakan penyuluh untuk menyampaikan informasi baru sebatas media cetakan seperti booklet, leaflet dan majalah pertanian bahkan alat peraga yang digunakan pada proses belajar dengan petani hanya berupa kertas plano sehingga audience mengalami kejenuhan karena pada umumnya hanya dalam bentuk ceramah. Hasil wawancara dengan penyuluh pada umumnya belum menggunakan media media massa dan elektronik sebagai media penyuluhan seperti radio, $\mathrm{TV}$, video, maupun jaringan internet bahkan website resmi Departemen Pertanian yaitu cyber extention, karena belum optimal tersosialisasi pada penyuluh. Penggunaan aplikasi cyber extension ini sangat penting dan diperlukan dalam menambah pengetahuan dan informasi penyuluh terkait kebutuhan informasi petani peternak. Belum optimalnya penggunaan cyber extension ini disebabkan banyak faktor diantaranya belum adanya fasilitas internet dan minimnya fasilitas laptop, padahal penggunaan media komunikasi ini sangat diperlukan agar supaya menarik perhatian dari petani peternak dan membangkitkan partisipasi dalam diskusi serta membantu proses belajar peternak.

Hasil penelitian menunjukkan bahwa ditinjau dari aspek kepemilikan sarana teknologi, maka kecenderuangan penilaian responden terhadap kepemilikan sarana teknologi informasi untuk mengakses informasi pertanian masih kurang optimal (30\%). Responden yang belum memiliki fasilitas informasi menganggap mahal dan mereka tidak mampu untuk mengoperasikannya apalagi berinternet. Optimalisasi pemanfaatan lebih cenderung pada akses internet media sosial. Namun bagi para penyuluh yang telah memiliki fasilitasi $(40,0 \%)$ cenderung punya sarana , namun tidak pernah dimanfaatkan. Sarana tersebut lebih banyak dimanfaatkan oleh anak-anak mereka yang mereka anggap mengerti cara berinternet. Distribusi berdasarkan karakteristik penyuluh terhadap teknologi informasi dapat dilihat pada Gambar 1, 2 dan 3. 
Motivasi Penyuluh dalam pemanfaatan teknologi informasi internet menunjukkan kecenderungan masih rendah $(66 \%)$. Hal ini disebakan karena penyuluh kebanyakan sudah senior dan akan memasuki masa pensiun sehingga kebutuhan yang lebih cenderung untuk aktualisasi diri. Penyuluh yang cenderung memiliki motivasi memanfaatkan informasi (34\%) hanya sebagai pelengkap materi penyuluhan dan tidak menjadikan sebagai materi utama dalam melaksanakan kegiatan penyuluhan.

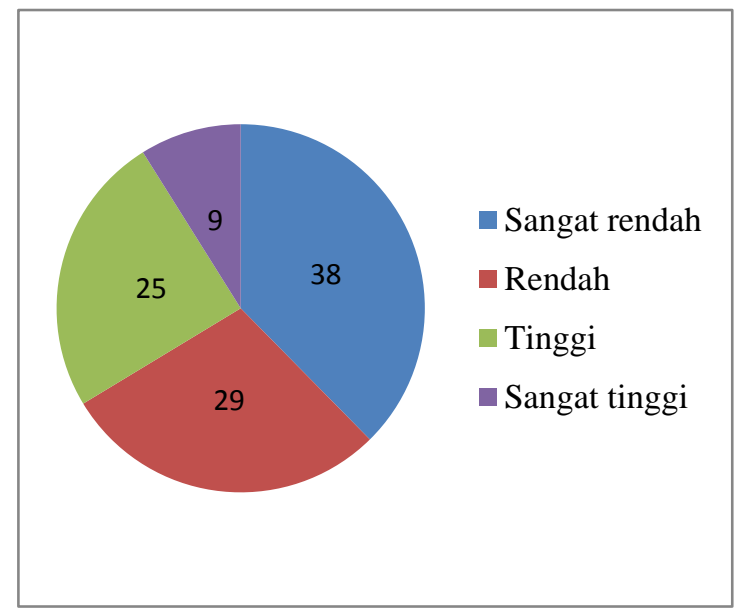

Gambar 1. Motivasi memanfaatkan informasi peternakan dengan internet

Penyuluh yang cenderung memiliki motivasi memanfaatkan informasi (34\%) hanya sebagai pelengkap materi penyuluhan dan tidak menjadikan sebagai materi utama dalam melaksanakan kegiatan penyuluhan. Sikap penyuluh terhadap teknologi informasi internet mempunyai kecenderungan sebagai pilihan mencari informasi hanya (14\%). Sikap tersebut diambil bila materi penyuluhan yang dibutuhkan tidak tersedia diberbagai sumber informasi tercetak yang baisa digunakan dalam sehari-hari dalam melaksanakan kegiatan penyuluhan, sedangkan sikap penyuluh yang cenderung masih menjadi pertimbangan $(37 \%)$ dengan alasan karena ketidaktahuan menggunakan internet. Apabila para penyuluh ingin mengakses internet maka akan meminta bantuan rekan kerjanya khususnya penyuluh THL. Itulah sebabnya, penggunaan cyber extension di Kabupaten Bulukumba relatif belum optimal. Akibatnya, pemanfaatan data atau informasi untuk perencanaan program, monitoring dan evaluasi relatif masih rendah.aplikasi sistim penyuluhan berbasis internet, cyber extension ini sebenarnya sangat mudah diakses oleh siapa saja, terutama para penyuluh pertanian, karena Kementerian Pertanian telah menyediakan hardware dan software pendukung aplikasi ini sampai ke tingkat kabupaten bahkan tingkat kecamatan.

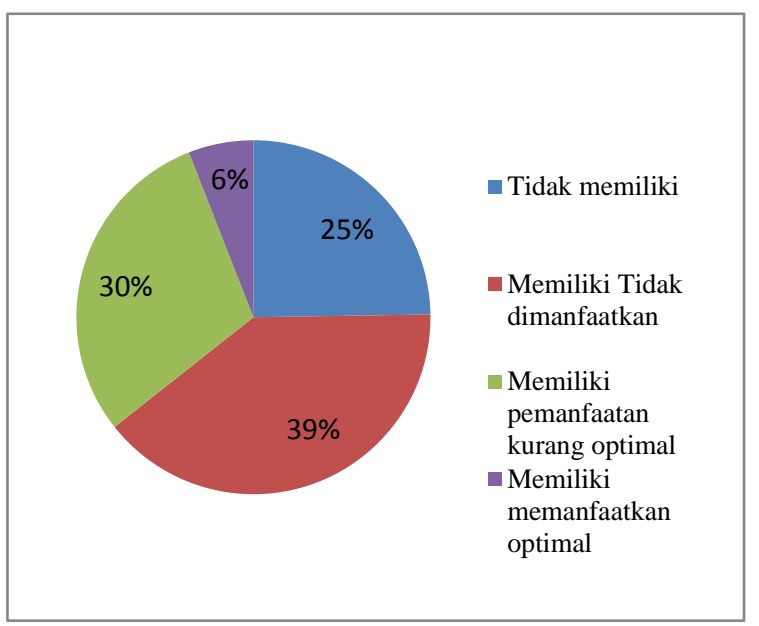

Gambar 2. Kepemilikan sarana teknologi informasi

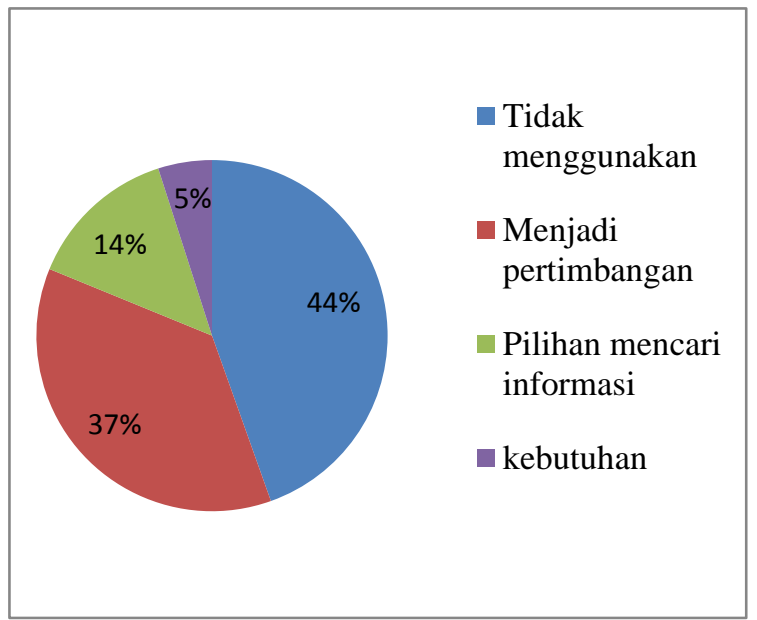

Gambar 3. Sikap penyuluh terhadap teknologi informasi

Namun kembali pada masih lemahnya sumber daya manusia baik ditingkat kelembagaan penyuluh maupun pada individu penyuluh sendiri, membuat aplikasi yang sengaja diprogramkan untuk memudahkan kerja penyuluh ini, justru belum bisa dimanfaatkan secara optimal oleh penyuluh. Kedepan, mestinya orang-orang yang duduk di kelembagaan penyuluh khususnya yang berada di tingkat kabupaten, harus merupakan sosoksosok yang menguasai teknologi informasi dengan baik, sehingga mereka dapat memanfaatkan media penyuluhan online cyber extension ini secara optimal. 


\section{KESIMPULAN}

Penyuluh telah mengetahui adanya cyber extension untuk mendapatkan informasi dalam membuat materi penyuluhan. Namun demikian, ternyata penyuluh belum mengetahui dengan baik tentang penggunaan cyber extension sebagai sumber informasi. Hal ini terlihat jumlah penyuluh yang telah memanfaatkan cyber extension masih rendah yaitu kurang dari 50\%. Untuk itu, perlu dilakukan upaya peningkatan dan optimalisasi penggunaan cyber extension untuk mendapatkan informasi teknologi melalui perbaikan fasilitas dan dukungan kelembagaan.

\section{DAFTAR PUSTAKA}

Depari, E. dan C. Mac Andrews. 1985. Peranan Komunikasi Massa dalam Pembangunan. Gadjah Mada University Press. Yogyakarta.

Hepi, H. 1994. Prilaku Komunikasi Sadar Pangan dan Gizi pada Akseptor KB Mandiri dan Faktor-faktor yang Berhubungan. Tesis Program Pascasarjana Institut Pertanian Bogor. Bogor.

Listiana, I. Efendi, I. Mutolib, A. dan Rahmat, A. 2019. The behavior of Extension Agents in Utilizing Information and Technology to Improve the Performance of Extension Agents in Lampung Province. Journal of Physics: Conference Series, 1155 (012004): 1-9.
Lionberger, HF. dan PH. Gwin, 1982. Communication Strategies : a Guide for Agricultural Change Agents. Danville illionis: The Interstate Printers \& Publisher.

Mardikanto, T. 2008. Penyuluhan Pembangunan Pertanian. Sebelas Maret University Press. Surakarta.

Mulyandari, R.S.H., Sumarjo., Lubis, D.P., Panjaitan, NK. 2010. Implementasi Cyber Extension Dalam Komunikasi Inovasi Pertanian. Jurnal Informa Pertanian Vol 19 No 2.

Rogers, Everett M and Floyd F, Schoemaker. 1985. Communication of Innovation : Cross Culture Approach. The Free Fress. New York.

Sugiyono, 2011. Metode Penelitian Kuantitatif dan Kualitatif dan $R \& D$. Alfabeta. Bandung.

Pujiana, T. Arianti, D. Dan Mutolib, A. 2019. Persepsi Stakeholder Terhadap Pengembangan Badan Usaha Milik Desa (Bumdes) Di Sungai Langka, Kecamatan Gedong Tataan Kabupaten Pesawaran. Mimbar Agribisnis: Jurnal Pemikiran Masyarakat Ilmiah Berwawasan Agribisnis, 5(2): 145-155.

Yanfika, H. Listiana, I. Mutolib, A. dan Rahmat, A. 2019. Linkages between Extension Institutions and Stakeholders in the Development of Sustainable Fisheries in Lampung Province. Journal of Physics: Conference Series, 1155 (01201): 1-9. 